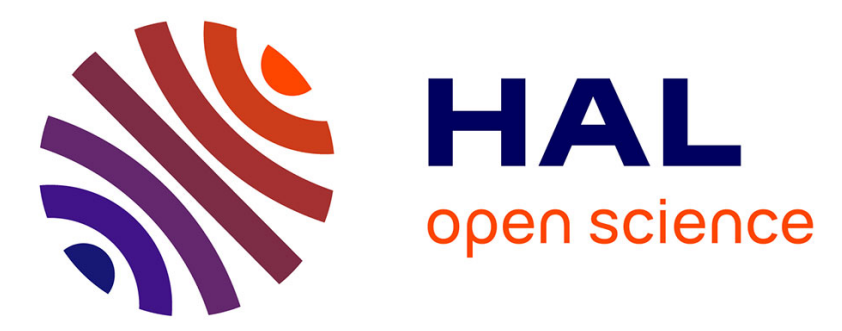

\title{
Organocatalytic sequential ring-opening polymerization of a cyclic ester and anionic polymerization of a vinyl monomer
}

Robert Mundil, Franck Kayser, Audrey Favrelle-Huret, Grégory Stoclet, Philippe Zinck

\section{To cite this version:}

Robert Mundil, Franck Kayser, Audrey Favrelle-Huret, Grégory Stoclet, Philippe Zinck. Organocatalytic sequential ring-opening polymerization of a cyclic ester and anionic polymerization of a vinyl monomer. Chemical Communications, 2020, 56 (58), pp.8067-8070. 10.1039/D0CC02906H . hal03230829

\section{HAL Id: hal-03230829 \\ https://hal.univ-lille.fr/hal-03230829}

Submitted on 20 May 2021

HAL is a multi-disciplinary open access archive for the deposit and dissemination of scientific research documents, whether they are published or not. The documents may come from teaching and research institutions in France or abroad, or from public or private research centers.
L'archive ouverte pluridisciplinaire HAL, est destinée au dépôt et à la diffusion de documents scientifiques de niveau recherche, publiés ou non, émanant des établissements d'enseignement et de recherche français ou étrangers, des laboratoires publics ou privés.

\section{()ㅜㅇㅜ}

Distributed under a Creative Commons Attribution - NoDerivatives| 4.0 International 


\title{
Organocatalytic sequential ring-opening polymerization of a cyclic ester and anionic polymerization of a vinyl monomer
}

Received 00th January 20xx,

\author{
Robert Mundil, ${ }^{\text {a }}$ Franck Kayser, ${ }^{a}$ Audrey Favrelle-Huret, ${ }^{a}$ Grégory Stoclet, ${ }^{b}$ and Philippe Zinck*a
}

Accepted 00th January 20xx

DOI: $10.1039 / \times 0 \times x 00000 x$

Organocatalysis has provided new tools for making block copolymers, in particular active species able to polymerize monomers of different chemical nature such as cyclic esters, cyclic carbonates and epoxides. We report herein the first example of an organocatalytic active species able to polymerize sequentially a cyclic ester, $\varepsilon$-decalactone, and a vinyl monomer, methyl methacrylate. The resulting block copolymer shows the properties of thermoplastic elastomers.

Organocatalyzed polymerizations have attracted much interest in the two last decades. ${ }^{1,2} \mathrm{~A}$ large variety of monomers can now be polymerized, including heterocycles such as cyclic esters, epoxides, cyclic carbonates, cyclic siloxanes, phospholanes, carboxyanhydrides, as well as acrylics and methacrylics. ${ }^{3}$ This large scope affords new tools for macromolecular engineering and notably block copolymers synthesis. ${ }^{4}$ The organocatalyzed sequential block copolymerization of monomers bearing the same chemical function is well documented in the literature, ${ }^{4}$ involving cyclic esters, cyclic ethers, cyclic carbonates and (metha)acrylics.

The sequential copolymerization between monomers of different chemical nature is obviously more difficult to reach, and much less documented. Organocatalysts systems allowing such hetero block copolymerization have been reported in the frame of ring-opening polymerizations. Several catalytic systems were reported for the sequential block copolymerization of cyclic esters and cyclic carbonates, including the 1,8-diazabicyclo[5,4,0]undec-7-ene amidine (DBU), ${ }^{5}$ Brönsted acids, ${ }^{6-9}$ and $\mathrm{H}$-bond catalytic systems ${ }^{10-13}$ as e.g thiourea/sparteine ${ }^{10}$ and base acid pairs. ${ }^{11} \mathrm{~A}$ temperature dependant switch has also been reported using the 1,5,7triazabicyclo[4.4.0]-dec-5-ene guanidine (TBD), allowing the

\footnotetext{
a. Univ. Lille, CNRS, Centrale Lille, Univ. Artois, UMR 8181 - UCCS - Unité de Catalyse et Chimie du Solide, F-59650 Villeneuve d'Ascq, France.

b. Univ. Lille, CNRS, INRAE, Centrale Lille, UMR 8207 - UMET - Unité Matériaux et

Transformations, F-59000 Lille, France.

† Footnotes relating to the title and/or authors should appear here.

Electronic Supplementary Information (ESI) available: [details of any supplementary information available should be included here]. See DOI: 10.1039/x0xx00000x
}

formation of multiblock copolymers. ${ }^{14}$ The sequential ringopening copolymerization of a phospholane with lactide as a cyclic ester was reported using the DBU amidine. ${ }^{15}$ Switching from epoxide to cyclic ester ring-opening polymerization has also been achieved using carbene ${ }^{16}$ and phosphazene ${ }^{17}$ based catalysts, while switching from an epoxide to a cyclic carbonate can be realized using an ammonium fluoride catalyst. ${ }^{18}$

The difficulties encountered while trying to make block copolymers from monomers of different chemical nature has led to the development of multistep strategies, where the active species is switched to a new form able to polymerize the second monomer. ${ }^{19,20}$ For example, the base catalyzed ringopening polymerization of a cyclic ether is quenched in situ by introduction of a weak Brönsted acid. ${ }^{19}$ The resulting new active species can then catalyze the ring-opening polymerization of cyclic esters and carbonates, providing access to polyetherblock-polyester and polyether-block-polycarbonate copolymers. Some variations were proposed where a second base can be introduced for the second block after the Brönsted acid neutralization, ${ }^{21}$ providing access to block copolymers between low ring strained macrolactones and smaller lactones. These approaches allow the access to a wide scope of block copolymers. They are multistep and involve different catalytic/initiating systems.

A strategy based on multifunctional initiators has also been reported. The combination in a single molecule of a controlled radical polymerization initiator moieties with a hydroxyl group able to initiate an organocatalytic ring-opening polymerization allows the access to $e . g$ poly( $\varepsilon$-caprolactone)-block-poly(methyl methacrylate) (PCL-block-PMMA) copolymers. ${ }^{22,23}$ This approach involves additional synthetic steps of the initiator, and is not as versatile as a sequential processes, which should notably allow the access to triblock copolymers starting from a bifunctional co-initiator such as a diol for instance. 


\section{COMMUNICATION}

Table $1 \varepsilon$-decalactone $(\varepsilon-\mathrm{DL})$ polymerization mediated by the benzyl alcohol/t-BuP 4 catalytic system in $\mathrm{THF}$ at $25^{\circ} \mathrm{C}$

\begin{tabular}{|c|c|c|c|c|c|c|c|}
\hline Entry $^{a}$ & $t$-BuP 4 /benzyl alcohol ${ }^{b}$ & $\begin{array}{c}\text { Conversion }{ }^{\mathrm{c}} \\
{[\%]}\end{array}$ & $\begin{array}{c}M_{\mathrm{n}}^{\mathrm{Rld}} \\
{\left[\mathrm{kg} \cdot \mathrm{mol}^{-1}\right]}\end{array}$ & $\bigoplus^{\mathrm{RId}}$ & $\begin{array}{c}M_{\mathrm{n}}^{\mathrm{LSe}} \\
{\left[\mathrm{kg} \cdot \mathrm{mol}^{-1}\right]}\end{array}$ & $\bigoplus^{\mathrm{LS} \mathrm{e}}$ & $\begin{array}{c}M_{\mathrm{n}}^{\text {theof }} \\
{\left[\mathrm{kg} \cdot \mathrm{mol}^{-1}\right]}\end{array}$ \\
\hline 1 & 0.2 & 2 & - & - & - & - & - \\
\hline 2 & 0.4 & 35 & 11.6 & 1.30 & 8.3 & 1.26 & 6.0 \\
\hline 3 & 0.6 & 65 & 17.7 & 1.43 & 11.3 & 1.31 & 11.1 \\
\hline 4 & 0.8 & 100 & 19.5 & 1.52 & 14.4 & 1.39 & 17.0 \\
\hline $5^{g}$ & 1.0 & 100 & 19.8 & 1.66 & 12.1 & 1.54 & 17.0 \\
\hline
\end{tabular}

$\mathrm{a}[\varepsilon-\mathrm{DL}]_{0}=2 \mathrm{M}, n_{\varepsilon-\mathrm{DL}}=4 \mathrm{mmol}$, molar ratio of $\varepsilon-\mathrm{DL} / \mathrm{benzyl}$ alcohol $=100 / 1, V_{\text {total }}=2 \mathrm{ml}, t=1 \mathrm{~h} ;{ }^{\mathrm{b}} \mathrm{Molar}$ ratio of $t$-BuP $4 /$ benzyl alcohol; cDetermined by ${ }^{1} \mathrm{H}$ NMR; dSEC-RI in THF at $40{ }^{\circ} \mathrm{C}$ calibrated with polystyrene standards; eSEC-MALLS in THF at $40{ }^{\circ} \mathrm{C}$; ${ }^{\mathrm{f}} M_{\mathrm{n}}$ theo $=\left(n_{\varepsilon}\right.$ $\left.\mathrm{DL} / n_{\text {benzyl alcohol }}\right) \cdot M_{\varepsilon-\mathrm{DL}} \cdot \mathrm{conv}_{\varepsilon-\mathrm{DL}} ;{ }^{g} t=10 \mathrm{~min}$

Scheme $1 t$-BuP 4 phosphazene catalyzed ring-opening polymerization of $\varepsilon$-decalactone and sequential block copolymerization with methyl methacrylate

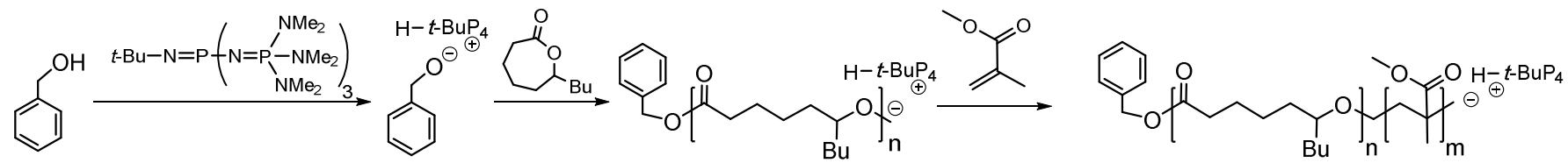

It should be noted that PCL-block-PMMA copolymers can also be synthesized sequentially using metallocene catalysts, 24,25 which can go with residual metal traces and eventually a related polymer coloration.

We report herein, for the first time, the sequential block copolymerization between a cyclic ester, and a vinyl monomer, using a single organocatalyst. The resulting new block copolymer self assembles in nanostructures that show mechanical properties typical of a thermoplastic elastomer.

Phosphazene bases seemed particularly suited to us for this purpose, as they allow the anionic polymerization of methacrylates such as methyl methacrylate $(M M A)^{26}$ as well as ring-opening polymerizations of various heterocycles. ${ }^{27,28}$ The key lies in finding appropriate monomer/catalyst combinations regarding the basicity of phosphazenes. $t-\mathrm{BuP}_{4}$, a very strong phosphazene base, $\$$ was reported for the anionic polymerization of MMA. ${ }^{26}$ The polymerization of $\varepsilon$ caprolactone is however too fast and uncontrolled with this catalyst 19,29 to envision a block copolymerization. $\varepsilon$ Caprolactone is also barely polymerized by the less basic $t-\mathrm{BuP}_{1} \S$ phosphazene $^{30}$ while the mild $t-\mathrm{BuP}_{2}{ }^{\S}$ affords the polymerization. ${ }^{17}$ We choose $\varepsilon$-decalactone $(\varepsilon$-DL) for our purpose, as this biobased lactone is known to be less reactive than $\varepsilon$-caprolactone in ring-opening polymerizations. ${ }^{31,32}$ The results of the polymerization of 100 eq. $\varepsilon$-DL vs. benzyl alcohol$^{\S \S}$ in the presence of the $t$-BuP 4 phosphazene (Scheme 1) are given in Table 1, and a typical NMR spectra is provided Fig. 1. A catalyst/initiator ratio of 0.4 is necessary to observe the formation of a polymer in THF at $25^{\circ} \mathrm{C}$. Dispersities around 1.3/1.4 are obtained for values of 0.4 and 0.6 of this ratio, together with a reasonable agreement between calculated and measured number-average molecular weight. The conversion is increasing with the phosphazene loading, and a full conversion can be reached with 0.8 and 1.0 eq. of $t-\mathrm{BuP}_{4}$ at room temperature (entries 4 and 5, Table 1). For these higher loadings, a slight broadening of the molecular weight distribution is observed $(\Xi \approx 1.4 / 1.5$, see also Fig. S1 in the ESI) together with a deviation between experimental and theoretical molar mass values.

Fig. $1{ }^{1} \mathrm{H}$ NMR spectra of PDL, PMMA and PDL-block-PMMA

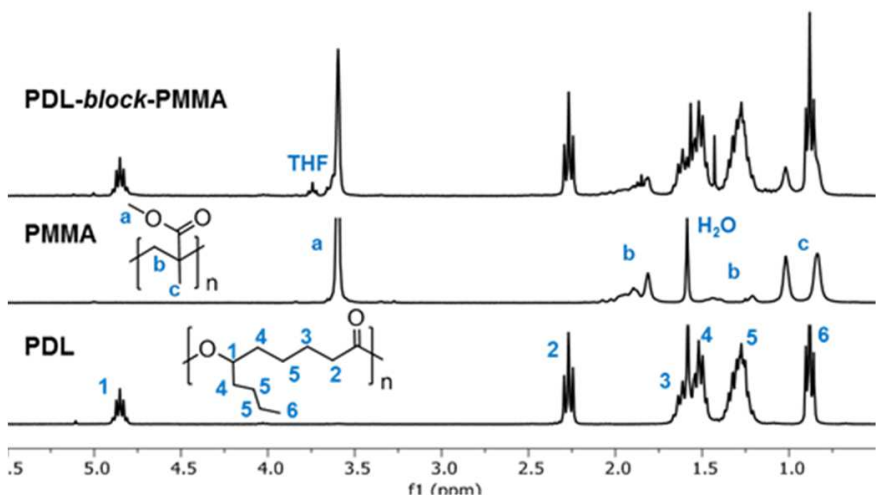


Fig. 2 SEC-RI chromatogram of poly( $\varepsilon$-decalactone)-blockpoly(methyl methacrylate) (PDL-block-PMMA) copolymer synthesis initiated by $t$-BuP 4 /benzyl alcohol ratio of 0.8 in THF at $25{ }^{\circ} \mathrm{C}$ together with the first PDL block (left side) and representative AFM (Atomic Force Microscopy) phase contrast image $\left(Z\right.$ range $=20^{\circ}$ ) of the block copolymer (right side)
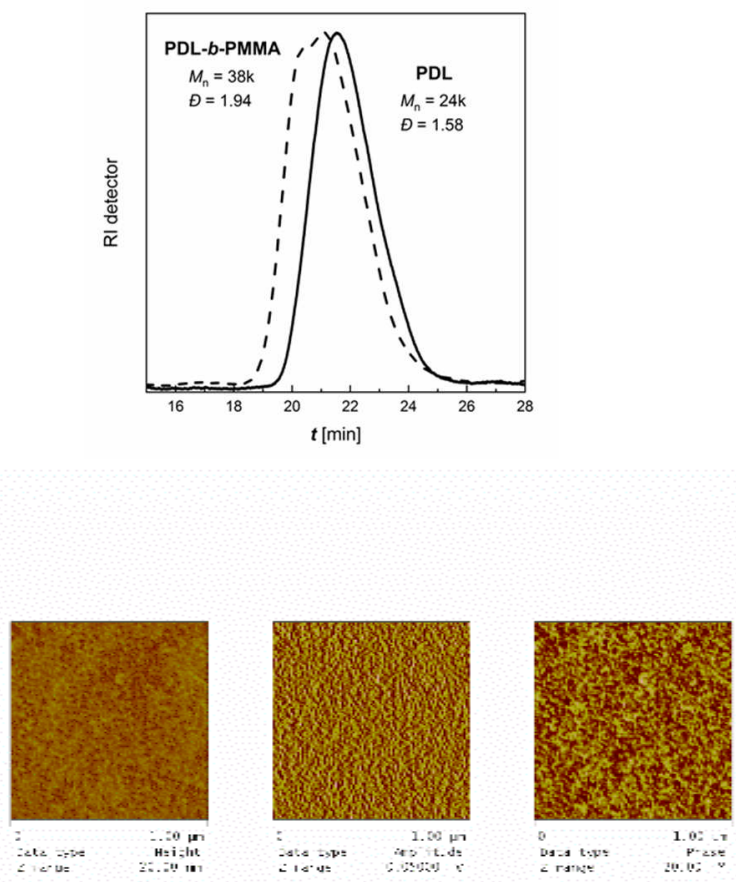

$112+$

Comparison of theoretical and absolute molar masses obtained by a light scattering detector together with low dispersity values $(\theta \approx 1.3)$ indicates the controlled character of the polymerization with 0.4 and 0.6 eq. of $t$-BuP 4 . Table 1 also shows a ca. $40 \%$ overestimation of the number-average molecular weight $M_{\mathrm{n}}$ measured using the refractive index detector (RI) and polystyrene standards.

The benzyl alcohol/t-BuP 4 catalytic system allows a full conversion in 10 minutes at room temperature (entry 5) and provides poly( $\varepsilon$-decalactone) (PDL) with a number-average molecular weight of $12.1 \mathrm{~kg} . \mathrm{mol}^{-1}(\mathrm{LS})$ and a dispersity $Ð=1.54$ in these conditions. Regarding other catalysts reported in the literature, the reaction rate is faster than that catalysed by the TBD guanidine, as, for the latter, $24 \mathrm{~h}$ reaction at $110^{\circ} \mathrm{C}$ are necessary to reach conversion higher than $80 \% .{ }^{32}$ Such a high reactivity prompted us to conduct a kinetic study that is provided in the ESI (Fig. S2). $\varepsilon$-DL polymerization catalyzed by 1.0 eq. of $t-\mathrm{BuP}_{4}$ is extremely fast, reaching full monomer conversion in two minutes at $25^{\circ} \mathrm{C}$ (black plot, Fig. S2). Polymerization catalyzed by 0.8 eq. of $t-\mathrm{BuP}_{4}$ is a bit slower and allows the full $\varepsilon$-DL conversion after eight minutes of polymerization, (red plot, Fig. S2).

A catalyst/initiator ratio of 0.8 seemed to us to be the best compromise to assess the ability of the active specie to switch to the polymerization of methyl methacrylate. The copolymerization was realized in the conditions of entry 4, with 100 eq. MMA added after letting ten minutes for the ringopening polymerization of $\varepsilon-D L$, following the kinetic study. The reaction was then allowed to proceed for an additional 35 minutes. The conversion of both monomers was found to be quantitative in these conditions. The increase of molar mass after the addition of MMA is represented by the shift of SEC-RI curve (Fig. 2, left side) with a slight broadening of the molecular weight distribution from ca. 1.6 to 1.9. The bimodal character of the molecular weight distribution may be due to the very high viscosity of the reaction medium, that could hamper monomer diffusion to some growing centres. This is further accompanied by the exothermic character of the polymerization of MMA at the early stages. We try to add MMA with a higher dilution, but the reaction did not succeed. The NMR spectrum of the block copolymer is shown in Fig. 1.

Such a poly( $\varepsilon$-decalactone)-block-poly(methyl methacrylate) copolymer was never reported in the literature to the best of our knowledge. This prompted to study the microstructure and the mechanical properties of the material. The SAXS (Small Angle X-ray Scattering) profile provided in the SI section (Fig. S3) shows correlation lengths of 10 to $20 \mathrm{~nm}$, highlighting a nanostructured material. The AFM picture (Fig. 1, right side) shows the presence of two distinct domains, i.e. soft and hard domains, confirming the nanostructured self-assembly of the copolymer. Tensile tests (which can be found in the ESI section as Fig. S4) led to a tensile modulus around 8.5 MPa, stress levels before breaking around $2 \mathrm{MPa}$ and strain at break as high as $200 \%$, which are characteristic of thermoplastic elastomers. Extension of the approach to other monomers together with thorough characterization of the so-formed materials are under course.

In conclusion, $\varepsilon$-decalactone can be polymerized in THF in the presence of the phosphazene base $t-\mathrm{BuP}_{4}$ and benzyl alcohol in a controlled fashion. A full monomer conversion can be obtained in a few minutes at room temperature, providing PDL of $M_{\mathrm{n}}{ }^{\mathrm{LS}}>10 \mathrm{~kg} \cdot \mathrm{mol}^{-1}$ and dispersities around 1.4-1.5. The sequential addition of methyl methacrylate highlights the living character of the polymerization, and provide the first example of an organocatalytic active species able to polymerize sequentially a cyclic ester and a vinyl monomer.

This work was funded by the FWV ELASTOPLAST Interreg Grant and the authors thanks the European Regional Development Fund (FEDER) and the University of Lille. Chevreul Institute (FR 2638), Ministère de l'Enseignement Supérieur, de la Recherche et de I'Innovation and Région Hauts de France are also acknowledged for supporting and funding partially this work. Financial support from Région Hauts de France and FEDER for both SAXS laboratory equipment is gratefully acknowledged. The authors also gratefully acknowledge Aurélie Malfait and Dr. Jonathan Potier for SEC measurements.

\section{Conflicts of interest}

There are no conflicts to declare. 


\section{Notes and references}

$\S$ The name and structure of the $t-\mathrm{BuP}_{1}, t-\mathrm{BuP}_{2}$ and $t-\mathrm{BuP}_{4}$ phosphazenes are provided in the $\mathrm{SI}$ section

$\S \S \mathrm{We}$ also assessed an amine and an amide as co-initiator, but the results were less convincing than those obtained with benzyl alcohol. The experiments are provided in the SI section as Table S2

1 N. E. Kamber, W. Jeong, R. M. Waymouth, R. C. Pratt, B. G. G. Lohmeijer and J. L. Hedrick, Chem. Rev., 2007, 107, 5813-5840.

2 A. P. Dove, ACS Macro Lett., 2012, 1, 1409-1412.

3 W. N. Ottou, H. Sardon, D. Mecerreyes, J. Vignolle and D. Taton, Prog. Polym. Sci., 2016, 56, 64-115.

4 S. Hu, J. Zhao, G. Zhang and H. Schlaad, Prog. Polym. Sci., 2017, 74, 34-77 and references herein.

5 J. Xu, F. Prifti and J. Song, Macromolecules, 2011, 44, 2660-2667.

6 Y. Shibasaki, H. Sanada, M. Yokoi, F. Sanda and T. Endo, Macromolecules, 2000, 33, 4316-4320.

7 A. Couffin, D. Delcroix, B. Martín-Vaca, D. Bourissou and C. Navarro, Macromolecules, 2013, 46, 4354-4360.

8 K. Makiguchi, Y. Ogasawara, S. Kikuchi, T. Satoh and T. Kakuchi, Macromolecules, 2013, 46, 1772-1782.

9 J. Liu, S. Cui, Z. Li, S. Xu, J. Xu, X. Pan, Y. Liu, H. Dong, H. Sun and K. Guo, Polym. Chem., 2016, 7, 5526-5535.

10 S. Tempelaar, L. Mespouille, P. Dubois and A. P. Dove, Macromolecules, 2011, 44, 2084-2091.

11 X. Wang, S. Cui, Z. Li, S. Kan, Q. Zhang, C. Zhao, H. Wu, J. Liu, W. Wu and K. Guo, Polym Chem, 2014, 5, 6051-6059.

12 X. Zhi, J. Liu, Z. Li, H. Wang, X. Wang, S. Cui, C. Chen, C. Zhao, X. Li and K. Guo, Polym. Chem., 2016, 7, 339-349.

13 S. Xu, H. Sun, J. Liu, J. Xu, X. Pan, H. Dong, Y. Liu, Z. Li and K. Guo, Polym. Chem., 2016, 7, 6843-6853.

14 P. Olsén, K. Odelius, H. Keul and A.-C. Albertsson, Macromolecules, 2015, 48, 1703-1710.

15 Y. H. Lim, G. S. Heo, S. Cho and K. L. Wooley, ACS Macro Lett., 2013, 2, 785-789.

16 J. Raynaud, C. Absalon, Y. Gnanou and D. Taton, J. Am. Chem. Soc., 2009, 131, 3201-3209.

17 J. Zhao, D. Pahovnik, Y. Gnanou and N. Hadjichristidis, Polym Chem, 2014, 5, 3750-3753.

18 H. Morinaga, Y. Ujihara and T. Endo, J. Polym. Sci. Part Polym. Chem., 2012, 50, 3461-3465.

19 J. Zhao, D. Pahovnik, Y. Gnanou and N. Hadjichristidis, Macromolecules, 2014, 47, 3814-3822.

20 Y. Liu, X. Wang, Z. Li, F. Wei, H. Zhu, H. Dong, S. Chen, H. Sun, K. Yang and K. Guo, Polym. Chem., 2018, 9, 154-159.

21 V. Ladelta, J. D. Kim, P. Bilalis, Y. Gnanou and N. Hadjichristidis, Macromolecules, 2018, 51, 2428-2436.

22 C. Aydogan, C. Kutahya, A. Allushi, G. Yilmaz and Y. Yagci, Polym. Chem., 2017, 8, 2899-2903.

23 H. Dong, Y. Zhu, Z. Li, J. Xu, J. Liu, S. Xu, H. Wang, Y. Gao and K. Guo, Macromolecules, 2017, 50, 9295-9306.

24 M. Yamashita, Y. Takemoto, E. Ihara and H. Yasuda, Macromolecules, 1996, 29, 1798-1806.

25 K. Kostakis, S. Mourmouris, G. Karanikolopoulos, M. Pitsikalis and N. Hadjichristidis, J. Polym. Sci. Part Polym. Chem., 2007, 45, 3524-3537.

26 T. Pietzonka and D. Seebach, Angew. Chem. Int. Ed. Engl., 1993, 32, 716-717.

27 J. Zhao, D. Pahovnik, Y. Gnanou and N. Hadjichristidis, Macromolecules, 2014, 47, 1693-1698.
28 J. Zhao, N. Hadjichristidis and Y. Gnanou, Polimery, 2014, 59, 49-59.

29 H. Yang, J. Xu, S. Pispas and G. Zhang, Macromolecules, 2012, 45, 3312-3317.

30 L. Zhang, F. Nederberg, R. C. Pratt, R. M. Waymouth, J. L. Hedrick and C. G. Wade, Macromolecules, 2007, 40, 4154-4158.

31 M. P. F. Pepels, M. Bouyahyi, A. Heise and R. Duchateau, Macromolecules, 2013, 46, 4324-4334.

32 P. Olsén, T. Borke, K. Odelius and A.-C. Albertsson, Biomacromolecules, 2013, 14, 2883-2890. 